\title{
The Treatment Strategy of Patients with Sleep Apnea Syndrome in Our Department and Subsequent Course
}

\author{
Takanori Fujioka*, Hideo Yamane \\ Department of Otorhinolaryngology, Graduate School of Medicine, Osaka City University, Osaka, Japan \\ Email: ${ }^{\text {tfujioka@med.osaka-cu.ac.jp }}$
}

Received 22 May 2014; revised 15 June 2014; accepted 2 July 2014

Copyright (C) 2014 by authors and Scientific Research Publishing Inc.

This work is licensed under the Creative Commons Attribution International License (CC BY).

http://creativecommons.org/licenses/by/4.0/

c) (i) Open Access

\section{Abstract}

It is known that acute or chronic heart failure can develop in patients with grave sleep apnea syndrome (SAS), and known to have the social problem including an accident and the decrease of the labor will. Several medical treatments are now available for SAS. We considered problems of the treatment based on the practice situation of our department about the present conditions and subsequent treatment. The subjects consisted of 306 patients. We measured Epworth Sleepiness Scale (ESS) and apnea hypopnea index (AHI) after polysomnography in all patients at the first time and 6 months later. So, it was found that AHI and ESS decreased when we could be treated in the SAS patients appropriately. It was confirmed that the choice of the appropriate regimen was important.

\section{Keywords}

\section{Sleep Apnea Syndrome, Apnea Hypopnea Index, Epworth Sleepiness Scale}

\section{Introduction}

Sleep apnoea syndrome (SAS) affects the social life of the patients for a decrease, a character change of daytime sleepiness (EDS) and the concentration by the decrease of the quality of night snoring, halfway awakening, frequent micturition. We are frequently complicated with circulatory disease and cerebrovascular disorder, respiratory failure such as hypertension, the ischemic heart disease with or without a symptom which contributes to the sudden death [1].

SAS is the disease concept that Guilleminault proposed in 1976 [2], prevalence in Japan is said to be men

*Corresponding author.

How to cite this paper: Fujioka, T. and Yamane, H. (2014) The Treatment Strategy of Patients with Sleep Apnea Syndrome in Our Department and Subsequent Course. International Journal of Otolaryngology and Head \& Neck Surgery, 3, $179-183$. 
$11.2 \%$ and women $2.0 \%$ [3]. It is assumed that the yellow-skinned races are higher in prevalence than Europe and America. And the main cause is thought to be the frame of the face [4].

In spite of these situations, the simple and easy, objective evaluation whether or not the treatment that the SAS patients received was really appropriate has not been performed to date. Therefore therapies are jumbled up close together, and it is in the present conditions that SAS patients are treated with continuous positive airway pressure (CPAP) easily. We showed treatment strategy in our department this time and considered it how long effect of treatment was found by real statistics.

\section{Objectives and Methods}

\subsection{Objective}

We intended for the patients who reported the symptoms such as somnolence, snoring, sleep apnoea, arousal night, the headache at awakening in the daytime, and consulted our department from August, 2005 to June, 2014. We performed an interview, and view examination of nose, pharynx, larynx with fiberscope, and intended for the person who conducted an examination for polysomnography (PSG) among the patients. It was decided that definition of SAS as apnea hypopnea index (AHI) was 5 or more and had a symptom of EDS.

\subsection{Method}

1) Confirmation of the symptom

We used Epworth Sleepiness Scale (ESS) which commonly spread as a method to evaluate a symptom [5]. This evaluates sleepiness to feel during work in eight kinds of situation with numerical value subjectively. We show that sleepiness is strong so that numerical value is big, and the perfect score is 24 points.

2) Measurement of AHI

We measured AHI in Alice4, Alice5 (Philips) and SomnoStarz4 (Fukuda Denshi). A specialized engineer conducted the analysis using attached software. We used AHI indicating the severity of the SAS in this study.

3) Other examination

All cases underwent chest, sinus and pharynx X-ray, electrocardiography and confirmed that it did not have the abnormality.

\subsection{Selection of the Regimen}

We show a summary of the common regimen choice in Figure 1. There was hypertrophy of palatine tonsil and adenoid and at first chose surgery when it was thought about with a main cause of the SAS and subsequentlyreexamined and introduced CPAP treatment, if necessary. However, such case was absent this time. When patient could use induction without problem, we examined CPAP treatment every month and set the appropriate pressure in reference to the report in the main body. We use REMstar ${ }^{\circledR}$ Auto with C-Flex ${ }^{\mathrm{TM}}$ or REMstar ${ }^{\circledR}$ Auto with A-Flex ${ }^{\mathrm{TM}}$. We used exclusive software (Encore Pro ver.1.8.49) for analysis of the use situation. We undergo endoscopis sinus surgery, deviatomy, conchotomy in the case attributable to a nasal cavity being narrow, when it was not surgery adaptation, we prescribed antiallergicdrugs and collunarium. We introduced dentist to the case that we thought to be caused by pharyngeal narrowness by retrognathism and asked it for oral appliance making.

\section{Result}

1) Constitution of the study patients

The study patients were 230 men from 14 years old to 84 years old (average of 47.4 years old), 306 people of 76 women in total, and the average body mass index (BMI) was $26.38 \mathrm{~kg} / \mathrm{m}^{2}$ (standard deviation 5.52 ). We show the details in Table 1, Table 2. We decided the treatment strategy on the basis of Figure 1, but there was one patient who were underwent adenoidectomy and tonsillectomy, and two patients were underwent sinus surgery even if AHI was less than 5. Even if other AHI was 5 or more, in less than 30 and the case that was not seriously ill, the person ordered periodical follow-up to 50 people who did not hope for treatment, but there was not the case had a medical examination subsequently. AHI was 40 or more as adaptation of the CPAP, but at first operated if there was surgery adaptation not having transduced CPAP in all cases. Also, oral appliance or nose 


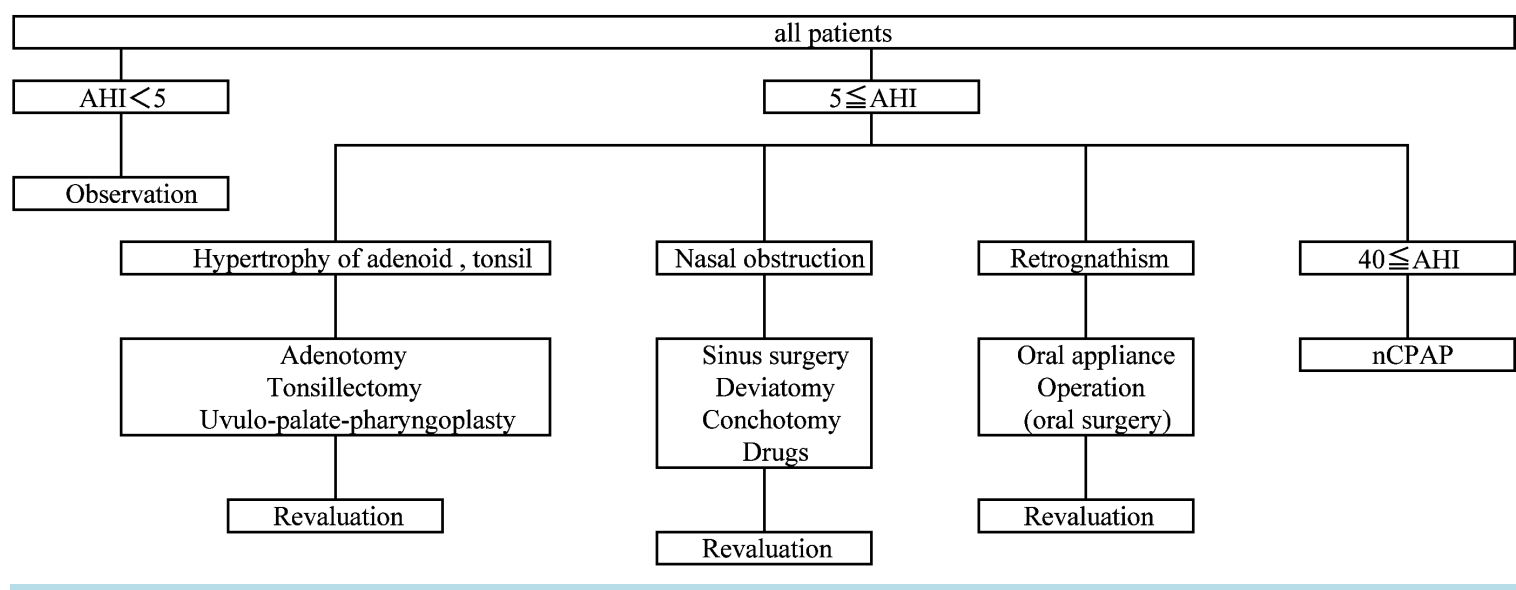

Figure 1. Outline in selection of medical treatment.

Table 1. Clinical characteristics of each medical treatment in this study.

\begin{tabular}{cccccccccc}
\hline Treatment & & Observation & Nasal drugs & Tonsillectomy & A \& T & OA & Sinus surgery & nCPAP & All patients \\
\hline Number & & 80 & 20 & 20 & 4 & 21 & 6 & 155 & 306 \\
Sex & (male) & 44 & 14 & 15 & 3 & 20 & 6 & 128 & 230 \\
& (female) & 30 & 6 & 5 & 1 & 1 & 0 & 27 & 76 \\
Age & $($ year $)$ & $47.8 \pm 16.2$ & $48.3 \pm 17.8$ & $28.3 \pm 11.2$ & $15.5 \pm 1.3$ & $57.3 \pm 16.8$ & $58.33 \pm 3.56$ & $52.2 \pm 14.6$ & $48.3 \pm 17.3$ \\
BMI & $\left(\mathrm{kg} / \mathrm{m}^{2}\right)$ & $24.92 \pm 4.54$ & $24.01 \pm 4.33$ & $26.99 \pm 7.05$ & $19.40 \pm 2.73$ & $24.27 \pm 4.62$ & $25.41 \pm 2.38$ & $29.63 \pm 4.82$ & $26.38 \pm 5.52$ \\
\hline
\end{tabular}

A\&T: Adenotomy + Tonsillectomy; OA: Oral appliance; Continuous values are shown as mean \pm SD. All numerical value is at the first examination.

Table 2. Analysis about transition of an index with the passage of time (paired t-test).

1) AHI

\begin{tabular}{lcccccc}
\hline Treatment & First & Number & 6 months & Number & P value \\
\hline Observation & & $10.23 \pm 5.45$ & 80 & ${ }^{*}$ & 0 & $*^{*}$ \\
Nasal drugs & $20.88 \pm 10.01$ & 20 & $14.02 \pm 8.05$ & 20 & $<0.001$ \\
Tonsillectomy & $38.19 \pm 30.55$ & 20 & $7.03 \pm 7.25$ & 20 & $<0.001$ \\
Adenotomy + Tonsillectomy & $13.00 \pm 9.14$ & 4 & $2.15 \pm 1.79$ & 4 & 0.061 \\
Oral appliance & & $55.33 \pm 17.05$ & 21 & $21.02 \pm 6.22$ & 21 & $<0.001$ \\
Sinus surgery & & $44.37 \pm 6.38$ & 6 & $15.02 \pm 5.23$ & 6 & $<0.001$ \\
nCPAP & (Good compliance) & $80.52 \pm 20.56$ & 105 & $3.12 \pm 1.55$ & 105 & $<0.001$ \\
& (Bad compliance + Drop out) & $52.33 \pm 11.35$ & 50 & $49.38 \pm 11.58$ & 50 & 0.492 \\
\hline
\end{tabular}

2) ESS

\begin{tabular}{lcccccc}
\hline Treatment & First & Number & 6 months & Number & P value \\
\hline Observation & $9.2 \pm 5.8$ & 80 & ${ }^{*}$ & 0 & $*^{*}$ \\
Nasal drugs & $8.5 \pm 4.2$ & 20 & $5.0 \pm 3.1$ & 20 & 0.006 \\
Tonsillectomy & $10.6 \pm 1.5$ & 20 & $3.1 \pm 3.0$ & 20 & $<0.001$ \\
Adenotomy + Tonsillectomy & $4.3 \pm 1.5$ & 4 & $1.3 \pm 1.9$ & 4 & 0.035 \\
Oral appliance & & $12.5 \pm 2.1$ & 21 & $4.3 \pm 3.8$ & 21 & $<0.001$ \\
Sinus surgery & & $8.5 \pm 5.3$ & 6 & $3.1 \pm 2.3$ & 6 & $*$ \\
nCPAP & (Good compliance) & $12.5 \pm 4.6$ & 105 & $3.1 \pm 1.3$ & 105 & $<0.001$ \\
& $\quad$ (Bad compliance + Drop out) & $9.8 \pm 4.9$ & 50 & $9.6 \pm 3.7$ & 50 & 0.653
\end{tabular}

Continuous values are shown as mean \pm SD. ${ }^{*}$ There were no patient or an analysis was impossible. This analysis was performed about the change as of 6 months after the first medical examination to each numerical value of the first medical examination. AHI effectively falls without case of nCPAP (Bad compliance + Drop out). ESS effectively falls without case of nCPAP (Bad compliance + Drop out). 
treatment were provided in the case that CPAP induction was not hoped for. We did the case that could use it more than four days a week about the use situation of CPAP with a good compliance group, a bad compliance group in lower than it more than six hours a day. When CPAP was not strongly available to unpleasantness and pain, we pushed forward other therapies, but all patients hoped for follow-up.

2) ESS

ESS of 306 people was 0 - 24 (average of 8.9, SD 5.0). Because we investigated SAS thoroughly for a case to suspect on an interview and a medical examination at initial diagnosis, we thought that patients with SAS were high and were found. It was 0 - 18 six months later (average of 5.8, SD 3.9).

3) AHI

AHI of 306 people was 0.6 - 99.3 (average of 29.68, SD 24.32). AHI was 5 or more, and the SAS and the thing which had a diagnosis were $81.66 \%$ of the whole in 256 people. Because the patients whom SAS was suspected in underwent this similar to above, we thought that high level appeared. It was 0.8 - 82.5 six months later (average of 18.35, SD 18.41).

4) Test of the index

AHI and ESS at initial diagnosis and at six months are shown in Table 2. We used paired t-test for this analysis. In case of Nasal drugs, Tonsillectomy, Adenotomy + Tonsillectomy, Oral appliance, Sinus surgery, CPAP (good compliance), we showed a significant decrease of AHI and ESS.

\section{Discussion}

To date respiratory internal medicine and psychiatry, neurology, otolaryngology were engaged in treatment of the SAS primarily. When the patients had a medical examination, an interview, confirmation, an imaging study of the presence or absence of upper airway obstruction disease, an endocrine examination by the drawing blood were performed, and treatment preferences have been performed in a case to suspect SAS as needed after having examined sleep. However, we introduce a CPAP uniformly and actually often provide the treatment that accepted a case when we can cope. Therefore there are many cases giving up treatment without being able to use it because of pain even if a CPAP is introduced after all. Also, surgery was performed well before, too, but we come to be avoided now by surgery because SAS may worsen. Surgery is not often undergone for the case that surgery is indicated for either. I think that we can perform it about choice of the treatment and adaptation of the surgery as otolaryngology most appropriately as the course which can confirm presence or absence of upper airway obstruction directly. In the case of the adaptaion of surgery, we perfume it after we explain enough for patient.

When treatment could be carried out in this examination definitely, it was shown that ESS and AHI decreased. If compliance is poor, the symptoms such as the apneic state or sleepiness do not improve even the similar treatment with CPAP. As a result, the burden to a body is not improved, and it is thought that a risk having cardiovascular disease increases. If treatment could not be provided for dysphoria to cure either, there was not a meaning, and there was little pain how, and it was confirmed to be the seriously worst whether you could establish the treatment plan that you could treat continuously. As one of the treatment, we think the surgery to be carried out positively. The pharynx extended operation such as Expansion Sphincter Pharyngoplasty [6], and Zpalatoplasty [7] is devised, too, but has not yet led to the spread. Also, it does not lead to the expansion of the surgery adaptation because the long-term results are not the situation to be obtained. There was a trend to detest surgery at one time, and it was only mainstream to introduce a CPAP into all cases. As a result, meaningless CPAP induction is carried out and thinks that, as a result, we were connected for the decrease of the level of the SAS treatment. We may not make SAS recover completely only by surgery, but are thought to be able to surely result in higher effect of treatment by the combination with the CPAP. It is necessary to choose the case, but should think the surgery to be useful as one of the therapeutic approaches. A new operative method such as ESP which we described some time ago is devised, and it is expected that good results appear. Surgery will be considered in one of the treatment strategy, and even internal medicine and psychiatry are expected if it can happen when they come to be able to provide the treatment that is high in the satisfaction for the patients.

However, it is a fact that many problems are left in future SAS treatment. First of all, a therapeutic approach is not generalized. The therapeutic approach varies according to diagnosis and treatment department and thinks that the unification is essential. Second, there is not a regimen to make it recover completely. It must continue for a long term, and it is one of the causes that the patients stop treatment when we introduce a CPAP once. Third, we make the patients without the symptom have a medical examination how, and it means whether you 
make it treat. Because we do not consult a hospital if there are few symptoms, we may be discovered after becoming severe SAS. If a symptom did not improve even when the patients started treatment after the examination, we couldn't continue the treatment. It is caused by the SAS treatment that does not commonly spread. In addition, it is thought to be important to the general public to improve consciousness for the SAS of the whole patients by enlightening SAS, and doing it. Thus, the medical staff cooperates with the public health, and the SAS is one of the diseases that must develop it.

\section{References}

[1] Rössner, S., Lagerstrand, L., Persson, H.E., et al. (1991) The Sleep Apnea Syndrome in Obesity: Risk of Sudden Death. Journal of Internal Medicine, 230, 135-141. http://dx.doi.org/10.1111/j.1365-2796.1991.tb00421.x

[2] Guilleminault, C., Tilkian, A. and Demont, W.C. (1976) The Sleep Apnea Syndrome. Annual Review of Medicine, 27, 465-484. http://dx.doi.org/10.1146/annurev.me.27.020176.002341

[3] Kayukawa, Y. (2002) Etiology of Sleep Disordered Breathing. Nipponhyoronsya, 2-8.

[4] Young, T., Palta, M., Dempsey, J., et al. (1993) The Occurrence of Sleep-Disordered Breathing among Middle-Aged Adults. New England Journal of Medicine, 328, 1230-1235. http://dx.doi.org/10.1056/NEJM199304293281704

[5] Johns, M.W. (1991) A New Method for Measuring Daytime Sleepiness: The Epworth Sleepiness Scale. Sleep, 14, 540545.

[6] Kenny, P., Pang, B. and Woodson, T. (2007) Expansion Sphincter Pharyngoplasty: A New Technique of Obstructive Sleep Apnea. Otolaryngology Head and Neck Surgery, 137, 110-114. http://dx.doi.org/10.1016/j.otohns.2007.03.014

[7] Micheal, F., Hani, Z.R., Ramakrishnan, V., Jonathan, P., et al. (2004) Z-Plalatoplasty: A Technique for Patients without Tonsils. Otolaryngology Head and Neck Surgery, 131, 89-100. http://dx.doi.org/10.1016/j.otohns.2004.02.051 
Scientific Research Publishing (SCIRP) is one of the largest Open Access journal publishers. It is currently publishing more than 200 open access, online, peer-reviewed journals covering a wide range of academic disciplines. SCIRP serves the worldwide academic communities and contributes to the progress and application of science with its publication.

Other selected journals from SCIRP are listed as below. Submit your manuscript to us via either submit@scirp.org or Online Submission Portal.
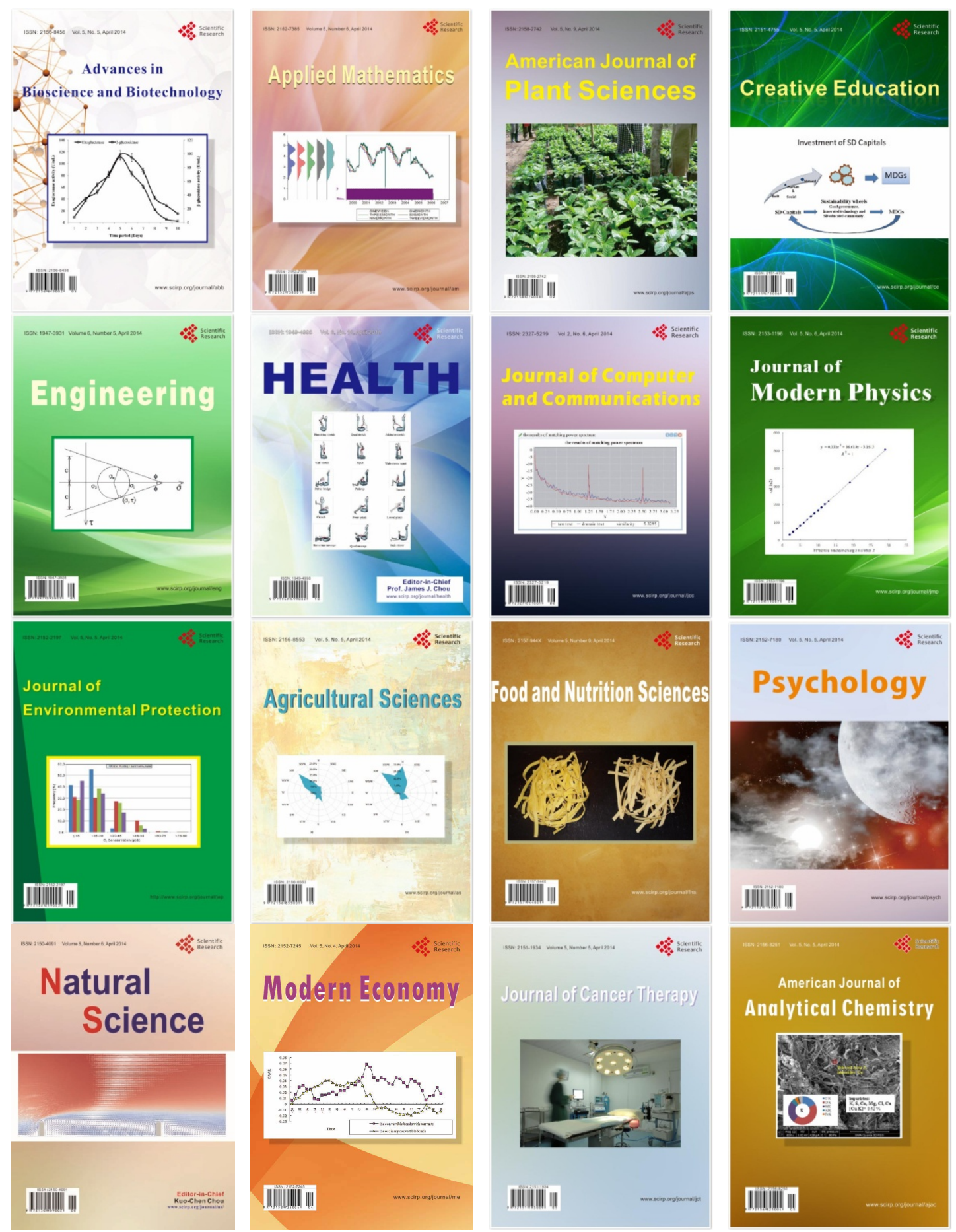